\title{
É possível a Ética do discurso de Habermas PARA PESSOAS COM DEFICIÊNCIA ${ }^{1}$ \\ IS HABERMAS'S DISCOURSE ETHICS POSSIBLE FOR PEOPLE WITH DISABILITIES?
}

Ana Carolina SELLA ${ }^{2}$

Maria Cristina MULLER ${ }^{3}$

\begin{abstract}
RESUMO: o presente estudo objetiva discutir, em primeiro lugar, a possibilidade de participação de pessoas com deficiência(s) no discurso, na ação e na interlocução. Em segundo lugar, analisa-se a Ética do Discurso de Jürgen Habermas e sua relação com a possibilidade de participação de pessoas com deficiência(s) no discurso, na ação e na interlocução; essa ideia é corroborada pelo fato de defensores e autodefensores de pessoas com deficiência sugerirem que a teoria de Habermas e sua Ética do Discurso deveriam servir como base para a busca/luta por equidade de respeito e de oportunidades. Apesar de a teoria de Habermas parecer referir-se apenas a pessoas que são capazes de falar por si mesmas "naturalmente", isto é, a pessoas que não necessitam de modificações ambientais para participarem do discurso, da ação e da locução, a Ética do Discurso de Habermas levanta uma questão urgente a ser enfrentada pela sociedade humana: o respeito à pluralidade humana.
\end{abstract}

PALAVRAS-CHAVE: Educação Especial. Pessoa com deficiência. Ética. Comunicação. Discurso.

\begin{abstract}
The present study aims to discuss the possibility of people with disabilities participating in discourse, action, and interlocution. Additionally, the study analyzes Jurgen Habermas's Discourse Ethics and its relation to how people with disabilities may be led to participate in discourse, action, and interlocution. This idea is corroborated by the fact that advocates and self-advocates have suggested that Habermas's theory and his Discourse Ethics should support the search / struggle for equal opportunities. Despite the fact that Habermas's theory seems to refer only to people who are capable of talking for themselves "naturally" (i.e., people who do not need environmental modifications to participate in discourse, action, and interlocution), Habermas's Discourse Ethics raises an urgent issue to be faced by human society: respect for human plurality.
\end{abstract}

KEYWORDS: Special Education. People with disability. Ethics. Communication. Discourse.

O presente estudo objetiva discutir, em primeiro lugar, a possibilidade de participação de pessoas com deficiência(s) no discurso, na ação e na interlocução. Em segundo lugar, analisa-se a Ética do Discurso de Jürgen Habermas e sua relação com a possibilidade de participação de pessoas com deficiência (s) no discurso, na ação e na interlocução; essa ideia é corroborada pelo fato de defensores e autodefensores de pessoas com deficiência (CONDELUCI, 2010; LEMESURIER et al., 2007) sugerirem que a teoria de Habermas (1989a) e sua Ética do Discurso deveriam servir como base para a busca/luta por equidade de respeito e de oportunidades.

\footnotetext{
${ }^{1}$ Agradecemos a Dorothy E. Nary pelo auxílio com a revisão bibliográfica acerca de auto-advocacia e assertividade e pelo auxílio em tornar o texto mais informativo a pessoas não familiarizadas com a teoria de Habermas.

2 The University of Kansas, Applied Behavioral Science Department. Research and Training Center on Independent Living. sella@ku.edu

${ }^{3}$ Universidade Estadual de Londrina, Departamento de Filosofia.cristinamuller@uel.br ou mcrismuller@hotmail. com. 


\section{INTRODUÇão}

A definição de deficiência tem passado por diversas modificações ao longo da história da humanidade (LONGMORE, 1987; PESSOTTI, 1984). Na atualidade, veem-se refletidas duas principais definições de deficiência no discurso e nas ações dos membros de nossa sociedade: uma baseada no modelo médico e uma baseada no modelo biopsicosocial. A definição médica carrega em si a ideia de que a deficiência é um "problema" médico que limita a vida do indivíduo. A partir disso assevera-se que as atitudes a serem tomadas em relação a este "problema" se referem a buscas pela "cura" deste "problema". A segunda definição de deficiência é mais recente e advém das propostas da Organização Mundial de Saúde presentes na reformulação da Classificação Internacional de Funcionalidade, Incapacidade e Saúde, ocorrida em 2001 (ORGANIZAÇÃO MUNDIAL DE SAÚDE, 2003). Tal definição propõe que se olhe para a deficiência como um fenômeno biopsicosocial e integrado da funcionalidade, da incapacidade e da saúde humana. Nesta segunda definição, há uma ênfase não apenas nas Funções e Estruturas do corpo, mas também nas Atividades e Participação e nos Fatores Ambientais que determinam a deficiência: as atividades sociais e os diferentes ambientes são inacessíveis; eles não acomodam os indivíduos de forma que possam exercer o seu potencial. É esta falta de acessibilidade e de acomodação que gera a falta de equidade de oportunidades e de respeito a todos os indivíduos em suas semelhanças e diferenças. A deficiência, então, é uma condição gerada por esta falta de acessibilidade e equidade de oportunidades.

Em teoria, segundo esta perspectiva da Organização Mundial de Saúde, mudanças nos ambientes físicos e sociais deveriam proporcionar equidade, respeito e oportunidades a todos. A partir dessa compreensão, defensores e autodefensores (CONDELUCI, 2010; LEMESURIER et al., 2007) de pessoas com deficiência têm argumentado que a teoria de Habermas (1989a), em geral e a Ética do Discurso, em específico, deveriam servir como base na busca/luta por equidade de respeito e de oportunidades. Segundo esta ética, o que torna possível a equidade e o respeito a todos é a participação no discurso, na ação e na interlocução. Mas será possível a utilização de tal ética quando se tem em vista a busca pelo respeito e oportunidade de pessoas com deficiência?

A Ética do Discurso de Habermas (1989a) é conhecida por sua sugestão de que a racionalidade e a argumentação deveriam guiar os seres humanos no processo de decisão daquilo que faz sentido e daquilo que aceitam como correto para suas vidas. Em sua teoria, Habermas privilegia a comunicação endereçada ao acordo mútuo, isto é, ao entendimento, e propõe que, para que esse seja alcançado, todas as pessoas devem ser capazes de participar da enunciação do discurso, da ação e da interlocução, especialmente naquilo que se relaciona à sua vida. Assim, as normas que encontram o assentimento de todos os concernidos enquanto participantes de um discurso prático podem reclamar validez (HABERMAS, 1989a). É nesse sentido que a oportunidade de participação para inclusão e a equidade são abordadas na presente investigação, isto é, para que haja entendimento em relação 
à participação, à inclusão e à igualdade, todos os afetados pelas decisões devem dela participar.

Antes de iniciar a discussão, porém, deve-se definir o que será entendido, no contexto do presente trabalho, por: 1) educação; 2) inclusão e 3) deficiência. 1) Educação é aqui entendida como qualquer evento no qual estejam envolvidos processos de ensinar e aprender, ou seja, qualquer evento ocorrido na sociedade e nos grupos constitutivos destas. A educação é responsável pela manutenção e perpetuação da cultura humana a partir da transposição, às gerações que se seguem, dos modos culturais de ser, estar e agir necessários à convivência e ao ajustamento de um membro no seu grupo ou sociedade. 2) Inclusão aqui é definida pela possibilidade de inclusão no discurso, na ação e na interlocução de todas as pessoas que possam ser afetadas por uma dada situação, tenham essas pessoas deficiência ou não. A inclusão é vista enquanto processo de humanização que leva o indivíduo a fazer parte de todas as esferas concernentes à vida humana, podendo opinar e fazer escolhas em cada uma delas. 3) No presente trabalho entende-se deficiência ${ }^{4}$ conforme a definição disposta no Decreto 3.956, de 8 de outubro de 2001 - a qual reflete, de certa forma, a definição da Organização Mundial de Saúde de 2001 - "uma restrição física, mental ou sensorial, de natureza permanente ou transitória, que limita a capacidade de exercer uma ou mais atividades essenciais da vida diária, causada ou agravada pelo ambiente econômico e social" (BRASIL, 2001, p. 3). Este trabalho trará, em alguns momentos, o foco sobre a deficiência intelectual ${ }^{5}$, contudo cabe generalizar esta discussão a diferentes deficiências, nos mais diferentes níveis de severidade.

4 A legislação básica que atualmente trata das questões acerca do apoio e integração social de pessoas com deficiência no Brasil é: Constituição Federal; Lei n ${ }^{\circ} 7.853$, de 24 de outubro de 1989; Decreto no 3.298 , de 20 de dezembro de 1999; Decreto ${ }^{\circ}$ 3.956, de 8 de outubro de 2001; Lei ${ }^{\circ} 10.436$, de 24 de abril de 2002; Portaria ${ }^{\circ}$ 2.678/02; Decreto $n^{\circ}$ 5.296, de 2 de dezembro de 2004; Lei de Diretrizes e Bases da Educação - 9394/96; Política Nacional de Educação Especial, 2008; Decreto no 6.094/2007; Decreto 6.571/2008; Plano Nacional de Educação - Educação Especial. Parte dessa legislação, por sua vez, se embasa na Convenção da ONU Sobre os Direitos das Pessoas com Deficiência de 2006 e na Declaração de Salamanca Sobre Princípios, Políticas e Práticas na Área das Necessidades Educativas Especiais de 1994.

${ }^{5}$ Habermas analisa a construção da moral a partir da ótica do estruturalismo genético de Piaget e Kohlberg (HABERMAS, 1989a; 1989b). As bases utilizadas por Habermas derivaram das asserções deste autor de que a construção da moral passa por três estágios: o pré-convencional, o convencional e o pós-convencional. Segundo tal visão, deficiências severas provavelmente não permitem ao indivíduo atingir o nível de moralidade chamado pós-convencional, o qual, teoricamente, possibilita que o indivíduo edifique uma ética do discurso. Se as limitações estruturais e funcionais, derivadas de deficiências severas, forem tomadas de forma literal, sem se atentar para o papel do ambiente social e físico e sua inacessibilidade, poder-se-ia concluir que essas pessoas não podem participar efetivamente do processo discursivo. Há estudos baseados na teoria piagetiana que argumentam que pessoas com deficiência não são capazes de aprender, muito menos de edificarem uma ética do discurso. Apesar deste ponto de vista estruturalista genético estar presente na obra de Habermas, o presente trabalho o problematiza. Conforme apontado pela definição da Organização Mundial de Saúde (2001), a deficiência implica, em parte, um fenômeno socialmente construído. Portanto, diminuições nas barreiras, físicas e sociais, e o desenvolvimento de formas de comunicação e de ensino alternativas, que gerem ou aumentem a acessibilidade de pessoas com deficiência a todas as esferas sociais, deveriam levar não apenas à maior participação destas pessoas nestas esferas, mas também a modificações na definição daquilo que é dado como válido em termos do discurso, da ação e da interlocução. 


\section{Desenvolvimento}

O método adotado para o desenvolvimento da pesquisa constitui-se de análise teórico-prática dividida em quatro momentos principais: 1) análise teóricoconceitual dos escritos de Habermas a partir de uma abordagem hermenêutica dos textos; 2) descrição de estudos acerca da possibilidade de ensino de habilidades de escolha, comunicação e autodefensoria a pessoas com deficiência; 3) interposição dos estudos acerca da comunicação de pessoas deficientes e da teoria da ação comunicativa de Habermas; e 4) discussão sobre a possibilidade de pessoas com deficiência participarem efetivamente do discurso, da ação e da interlocução. Assim, o presente trabalho inicialmente descreve as principais características que compõem os processos linguísticos de entendimento mútuo e que garantem a inclusão e a igualdade segundo a teoria de Habermas; a seguir, são apresentadas pesquisas empíricas acerca do empoderamento de pessoas com deficiência e da necessidade de se fornecerem ferramentas para que essas pessoas possam participar na comunidade e reivindicar seus direitos; em seguida, discute-se a possibilidade de beneficiários da Educação Especial alcançarem efetivamente uma posição de inclusão e igualdade, tendo como fundamentação a compreensão de Habermas (1989a) acerca do que é uma comunicação endereçada ao entendimento mútuo; finalmente, aborda-se a questão da inclusão e da igualdade, considerandose as deficiências severas e as ferramentas que se têm disponíveis para possibilitar a comunicação e participação desses indivíduos.

\subsection{Propedêutica da ética do discurso de Habermas}

Os seres humanos têm inúmeras motivações que podem ser divergentes ou convergentes às de outros seres humanos. Essas motivações precisam ser harmonizadas para a vida em sociedade ser possível. De acordo com Habermas (1989a), a harmonização dos interesses divergentes se dá pela busca do entendimento. Compreende-se entendimento como uma comunicação endereçada ao acordo mútuo. A teia das relações humanas impõe a necessidade do estabelecimento de normas que rejam essas interações. Algumas dessas normas fazem parte do cotidiano das pessoas e sequer são percebidas; outras, porém, devido a sua complexidade, exigem processos de formalização. Para Habermas (1989a), é necessário verificar a correção de qualquer uma das normas, não por uma única pessoa ou por um grupo de pessoas, mas por todos aqueles que são afetados pela norma em questão. Essa verificação deveria seguir procedimentos racionais. Segundo Habermas (1989a), o procedimento para verificar a correção moral das normas deveria ser o de perguntar se tal norma seria aceitável para todos os afetados por ela. A isso Habermas (1989a) nomeia de situação ideal de fala.

Habermas (1989a) afirma que os fenômenos morais podem ser analisados através de uma investigação formal-pragmática da ação comunicativa. A ação comunicativa - os atos de fala explícitos - é uma ação que serve para compelir membros da sociedade a aderir a normas sociais implícitas. Os membros da 
sociedade são motivados a aderir a estas normas através do efeito ilocucionário existente no discurso dos outros (HABERMAS, 1989a).

Habermas comunga da ideia de que os atos de fala podem ser de três tipos: Locucionários $^{6}$, Ilocucionários e Perlocucionários ${ }^{7}$. Os atos de fala ilocucionários, além de pronunciarem uma locução, geram uma ação, provocam uma ação. Para Habermas (1989a), em virtude doefeito ilocucionárionos processos deentendimento mútuo, os atores levantam pretensões de validade. A pretensão de validade diz respeito àquilo que é digno de ser reconhecido, ou seja, é a garantia que o falante oferece para que haja entendimento ou para que o entendimento seja possível. Ao buscar garantir a pretensão de validade no entendimento, devem-se observar quatro subdivisões da pretensão de validade: a pretensão de verdade, a pretensão de retitude ou correção, a pretensão de veracidade ou sinceridade e a pretensão de inteligibilidade. A pretensão de inteligibilidade pode ser compreendida como condição anterior às outras três pretensões de validade, isto é, sem inteligibilidade, a busca pelo entendimento mútuo não é possível, pois é ela que estabelece as condições de comunicação entre os falantes. Se não há condições de os falantes compreenderem uns aos outros, não há como se estabelecer o entendimento. A pretensão de verdade se refere ao mundo objetivo, à existência de um estado de coisas; dá razões - explica discursivamente -, isto é, estabelece discursivamente constatações acerca do mundo. A pretensão de correção se relaciona ao mundo social, ordenando-o e normatizando-o discursivamente - discurso racional. Finalmente, a pretensão de sinceridade se refere ao mundo subjetivo, ou àquilo que acontece dentro do indivíduo; estabelece consistência no comportamento do indivíduo, expressa consequências da ação (HABERMAS, 1989a).

A pretensão que está ligada à realidade social é a pretensão de correção (ou pretensão normativa). Esta pretensão será o foco do presente trabalho, pois está ligada ao mundo social, no qual as normas e a ordem vigentes deveriam servir para incluir todas as pessoas afetadas pela norma ou pela ordem que está sendo estabelecida. Essa pretensão tem uma dependência recíproca da linguagem e do mundo social. Isso significa que ela só pode ser considerada válida quando é aceita por todos aqueles cujo comportamento é afetado por essa pretensão. Uma pretensão normativa não pode ser imposta a um grupo ou a uma sociedade. Para ser aceita uma dada pretensão normativa, as razões devem ser expostas através do discurso. As pessoas podem até viver e aceder a uma norma porque eles não veem nenhuma alternativa, mas essa norma não terá validez social em longo prazo enquanto não for aceita por todos aqueles a quem é endereçada. A imposição de normas pode ser obtida a partir do uso da violência ou de algum tipo de sanção, mas de imposição não se obtém validez. Se a validez de uma norma não está claramente evidente, essa norma provavelmente não será aceita e provavelmente será abandonada. Por esse fato, as pretensões normativas têm um papel tão importante nas práticas

\footnotetext{
${ }_{6}^{6}$ Postos de forma simples, atos de fala locucionários são aqueles que dizem respeito apenas a locuções, ao ato de dizer, não provocando ação em seus ouvintes.

${ }^{7}$ Atos de fala perlocucionários dizem respeito aos efeitos que o ato ilocucionário provoca no ouvinte. 
diárias de um grupo ou de uma sociedade: elas influenciam as ações que indicam um acordo implícito em se viver e em se tratar uns aos outros de certa forma. Tendo isto em vista, como são regidas as argumentações voltadas ao acordo?

Habermas (1989a) afirma que, para reger tal teoria da argumentação, a qual fornece a base para um agir comunicativo que pretenda o entendimento, é necessário que haja um princípio-ponte que permita que as vontades singulares se convertam em vontade comum; nesse sentido esse princípio-ponte se converte em princípio moral que serve como regra de argumentação, uma vez que para se obter o consenso é preciso o assentimento de todos os concernidos, sendo válidas apenas as normas que expressarem vontade universal. Habermas (1989a, p. 84) explica que esse princípio moral deve ser compreendido de forma a excluir como inválidas as normas que não possam encontrar o assentimento qualificado de todos os concernidos possíveis. O princípio-ponte deve assegurar que só sejam aceitas como válidas as normas que exprimam uma vontade universal.

Para Habermas (1989a), este princípio de universalização não se esgota na exigência de que as normas morais devem ter a forma de proposições normativas, universais e incondicionais. É preciso que as normas mereçam o reconhecimento por parte de todos os concernidos. Isto significa, para Habermas (1989a), que não basta que alguns indivíduos examinem se querem que entre em vigor uma norma em relação a consequências e efeitos colaterais que ocorreriam se todos a seguissem. Não basta, também, que esses indivíduos analisem se todos os outros que se encontram em uma situação semelhante à sua gostariam da entrada em vigor desta norma. Nestes dois casos, a formação do juízo é relativa apenas à posição e perspectiva de alguns.

Para exprimir a vontade universal e haver legitimidade é necessário que o ponto de vista seja imparcial. Conforme afirmado por Habermas

[...] Só é imparcial o ponto de vista a partir do qual são passíveis de universalização exatamente aquelas normas [...] que podem contar com o assentimento universal, e por isso merecem o reconhecimento intersubjetivo. A formação imparcial do juízo exprime-se [...] em um princípio que força cada um, no círculo dos concernidos, a adotar, quando da ponderação dos interesses, a perspectiva de todos os outros. (HABERMAS, 1989a, p. 86).

Sendo assim, toda norma válida deve satisfazer a condição de que as consequências e efeitos colaterais devem ser aceitos por todos os concernidos e a norma deve ser universalmente seguida. A satisfação resultante das consequências e efeitos colaterais devem advir de tal seguimento e aceitação universal.

Habermas (1989a) introduz, então, outra diferenciação entre o princípio de universalização (U) e o princípio que exprime a ideia fundamental da ética do discurso: o principio ético-discursivo(D). Oprincípioético-discursivo(D) pressupõe que uma norma só deve pretender validade quando todos os que possam ser concernidos por ela cheguem (ou possam chegar) a um acordo quanto à validade 
da norma. O princípio de universalização (U) é uma regra de argumentação que possibilita o acordo em discursos práticos e é apenas com sua fundamentação que se poderá dar o passo em direção à ética do discurso. Habermas (1989a) salienta que a versão por ele dada à U é uma versão que exclui a possibilidade de uma explicação monológica (referente ao indivíduo) desse princípio. Em Habermas (1989a), U rege apenas as argumentações entre diversos participantes, nunca rege as argumentações que os indivíduos possam empreender por si só, consigo mesmos. Este fato se dá porque os problemas que devem ser resolvidos nas argumentações morais não são passíveis de serem superados individualmente, somente em cooperação. As argumentações morais devem anular consensualmente os conflitos da ação, remontando a um acordo normativo.

Habermas afirma que este acordo deve expressar uma vontade comum e, para que as argumentações morais produzam um acordo desse gênero,

[...] não basta que um indivíduo reflita se poderia dar seu assentimento a uma norma. Não basta nem mesmo que todos os indivíduos, cada um por si, levem a cabo essa reflexão, para então registrar seus votos. O que é preciso é, antes, uma argumentação "real", da qual participem cooperativamente os concernidos. Só um processo de entendimento mútuo, intersubjetivo pode levar a um acordo que é de natureza reflexiva; só então os participantes podem saber que eles chegaram a uma convicção comum. (HABERMAS, 1989a, p. 88).

Após discorrer sobre a necessidade da cooperação entre todos os concernidos em relação a uma argumentação moral, Habermas (1989a) retoma outra questão do princípio da universalização: este princípio, que é regra da argumentação, é implicado por pressuposições de argumentação em geral. Essas pressuposições visam a produção "[...] de argumentos concludentes, capazes de convencer com base em propriedades intrínsecas e com os quais se pode resgatar ou rejeitar pretensões de validade." (HABERMAS, 1989a, p. 110).

Habermas (1989a) distingue três pressupostos argumentativos que deveriam estar presentes ao buscar-se o princípio da universalização: 1) pressupostos no plano lógico semântico dos produtos; 2) pressupostos no plano dialético dos procedimentos e 3) pressupostos no plano retórico dos processos. principais:

Em relação ao plano lógico-semântico, Habermas expõe três regras

(1.1) A nenhum falante é lícito contradizer-se. (1.2) Todo falante que aplicar um predicado $\mathrm{F}$ a um objeto $a$ tem que estar disposto a aplicar $\mathrm{F}$ a qualquer outro objeto que se assemelhe a $a$ sob todos os aspectos relevantes. (1.3) Não é lícito aos diferentes falantes usar a mesma expressão em sentidos diferentes. (HABERMAS, 1989a, p. 110).

No plano procedural, Habermas propõe duas regras (pressupostos): “(2.1) A todo falante só é lícito afirmar aquilo em que ele próprio acredita. (2.2) Quem 
atacar um enunciado ou norma que não for objeto da discussão tem que indicar uma razão para isso." (HABERMAS, 1989a, p.111).

E em relação aos aspectos processuais, Habermas aponta três pressupostos:

(3.1) É lícito a todo sujeito capaz de falar e agir participar de Discursos. (3.2) a. É lícito a qualquer um problematizar qualquer asserção. $b$. É lícito a qualquer um introduzir qualquer asserção no Discurso. c. É lícito a qualquer um manifestar suas atitudes, desejos e necessidades. (3.3) Não é lícito impedir falante algum, por uma coerção exercida dentro ou fora do Discurso, de valer-se de seus direitos estabelecidos nos pressupostos anteriores. (HABERMAS, 1989a, p.112).

Esses princípios e pressuposições propõem uma forma de argumentação e de ação que seja orientada ao discurso, à ação e à interlocução. Conforme enfatizado por Habermas (1989a), essas pressuposições foram construídas para se obter uma norma que pudesse vigorar a partir do predicado "igualmente boa para cada um dos concernidos". As próprias regras do Discurso têm conteúdo normativo ao tentarem evitar o desequilíbrio de poder ou a tentativa de alguns prescreverem ou induzirem aos demais aquilo que consideram bom para si próprios. "A forma da argumentação [...] deve possibilitar, não a imparcialidade do juízo, mas a ininfluenciabilidade ou autonomia da formação da vontade." (HABERMAS, 1989a, p. 92, grifo do autor). Mas, como garantir a participação de pessoas com deficiência e com dificuldades de comunicação nas esferas do discurso, da ação e da interlocução? Esse parece ser o primeiro desafio a ser enfrentado na busca por um processo inclusivo efetivo.

Estudos e movimentos advindos da Educação Especial no Brasil (e dos estudos das deficiências, em outros países) demonstram que esse desafio, apesar de ser grande, não deve ser visto como instransponível. A seguir foram descritas algumas pesquisas e movimentos de autodefensoria (GLAT, 2004) que tiveram como objetivo prático engajar pessoas com deficiências nas argumentações, discussões e escolhas relativas às normas e leis que fazem parte de suas vidas.

A busca por tais pesquisas e movimentos sociais, que representassem como a possibilidade de participação pode ocorrer desde que olhemos para a questão da acessibilidade e acomodações, envolveu a escolha de base de dados e de palavraschave que fossem acessíveis. Provavelmente, há outras pesquisas e movimentos que não foram aqui descritos ou mencionados. As bases de dados utilizadas foram: PsycInfo, PubMed, ERIC, Google Scholar, Google, Global Disabilities Rights e Association of University Centers on Disabilities. As palavras-chave utilizadas foram: autodefensoria, assertividade, comunicação funcional, suporte comportamental positivo, deficiência e habilidades e suas respectivas traduções para o inglês: self-advocacy, assertiveness training, functional communication, positive behavioral support, disability e skills. Foram encontrados diversos estudos, desde pesquisas participativas que utilizam a metodologia da pesquisaação e pesquisa participativa (BEAMISH; BRYER, 1999; GOODLEY; LAWTHOM, 
2005; SAMPLE, 1996; WARD; TRIGLER, 2001), até pesquisas que utilizam uma metodologia com controle experimental rigoroso (SIEVERT; CUVO; DAVIS, 1988).

Comoumdosmotivadoresdaelaboraçãodessetrabalhoéa problematização da possibilidade de incluir todos os envolvidos na tomada de decisão acerca da Educação Especial, foram escolhidas algumas das pesquisas encontradas como representativas das diferentes formas de promover a autodefensoria visando à participação, autonomia e escolhas para pessoas com deficiência. O leitor perceberá que a maior parte das pesquisas se refere a pessoas com deficiência intelectual, apesar de não se limitar a essas. Tal ênfase foi feita porque essas são as pessoas que menos têm exercido sua participação na formulação de leis e normas que regem sua vida quando se tem em vista a Educação Especial e os estudos das deficiências, pois a visão do senso comum ainda é, muitas vezes, a de que uma pessoa com deficiência intelectual não é capaz de aprender como fazer escolhas e como lidar com as consequências destas (BROWDER; COOPER; LIM, 1998; COOPER; BROWDER, 1998; RAWLINGS; DOWSE; SHADDOCK, 1995).

\subsection{AutOdefENSORIA, PROMOÇão De PARTICIPAÇão, AUTONOMIA E ESCOLHAS}

Beamish e Bryer (1999) utilizam uma metodologia baseada na colaboração entre pesquisadores e participantes para desenvolver um programa de avaliação de qualidade de um serviço de intervenção precoce em Queensland, na Austrália. Segundo os autores, apesar de essa metodologia ser encorajada para pesquisas com pessoas com deficiência, esse tipo de pesquisa demanda do pesquisador sair de sua posição de detentor do conhecimento e entrar na posição de aprediz. Em seu texto, os autores discutam a urgência de tornar pessoas com deficiência participantes do processo de tomada de decisões, especialmente em pesquisas e programas que determinam as normas e leis que regerão suas vidas. A seguir, os autores explicam em detalhes o que é uma pesquisa participativa e como tais pesquisas costumam ser definidas quando pessoas com deficiência estão envolvidas. Como os serviços se relacionavam à intervenção precoce (0-6 anos), os autores, pais das crianças e provedores do serviço optaram por envolver diversos segmentos da sociedade que pudessem representar diferentes interesses da população-alvo. Foram envolvidos administradores, políticos, outros pais, clínicos, pessoas de diferentes etnias, classes sociais, especialistas em diferentes áreas das deficiências, entre outros. O projeto teve duração de quatro anos, dividido em diversos estágios, gerado a partir de interações entre os interessados (acima citados) na questão. Após o desenvolvimento do programa de qualidade, este foi validado no próprio serviço e, a seguir, foi aplicado no país todo. Os autores detalham as vantagens e desvantagens deste tipo de pesquisa, salientando o fato de que os resultados obtidos foram socialmente validados por todos os constituintes.

Em 2008, Jurkowski e Ferguson foram além e utilizaram a metodologia participativa chamada Photovoice para engajar pessoas com deficiência intelectual no desenvolvimento de programas de pesquisa e de serviço que informariam as 
modificações de políticas públicas em Chicago, nos Estados Unidos. Os autores discutem as dificuldades de ensinar as habilidades básicas aos participantes, porém, uma vez ultrapassada esta barreiras, os autores concluem que Photovoice fornece uma forma de pessoas com deficiência intelectual refletirem sobre suas vidas e comunicarem suas perspectivas para as pessoas que costumam tomar as decisões acerca de suas vidas. Mais especificamente, os autores tomam o cuidado de levar as pessoas com deficiência intelectual para apresentarem suas questões aos políticos, desta forma garantindo que suas opiniões fossem ouvidas.

Tomando uma perspectiva mais experimental, Seivert, Cuvo e Davis (1988) ensinaram deficientes intelectuais a diferenciar entre situações nas quais havia uma possível violação de seus direitos e situações nas quais tais violações não ocorriam. Tais habilidades foram escolhidas, porque muitas vezes se ensinam os direitos das pessoas com deficiência apenas a partir de exemplos onde há violação de tais direitos. Como consequência, as pessoas não sabem diferenciar quando há, efetivamente, uma violação de seus direitos ou quando é apenas uma questão decorrente de situações econômicas ou interpessoais. Os pesquisadores utilizaram uma sequência de dicas, exemplos e contra-exemplos para ensinar as diferenças entre violações e não violações dos direitos dos participantes. Se os participantes não aprendessem a diferença entre as situações, os pesquisadores forneciam modelo sobre como os participantes deveriam agir: se seus direitos eram violados, os participantes encenavam como deveriam reivindicar seus direitos. Se não eram violados, os participantes eram ensinados a fazer pesquisas que pudessem clarificar a situação e as razões pelas quais se encontravam em uma dada situação. Os comportamentos aprendidos foram avaliados em situações reais, na comunidade. Houve uma melhora significativa na reivindicação de direitos, não apenas logo após o ensino das habilidades, mas após algum tempo sem o treino das habilidades. Os participantes passaram a utilizar estas habilidades em seu dia a dia, melhorando sua participação na comunidade.

Page et al. (1981) realizaram um estudo para avaliar o impacto de um treino de assertividade no comportamento de pacientes com deficiência intelectual severa de um programa de reabilitação. O treino consistia em sessões de relaxamento, explicações acerca do que era assertividade, tarefas de casa para os participantes, encenação de situações em que a assertividade seria necessária e feedback do grupo como um todo (pares e pesquisadores). Quando comparados a um grupo controle, que não recebeu o treino de assertividade, os participantes passaram a ser mais assertivos e passaram a perceber que suas ações geravam efeitos sobre as pessoas e o ambiente ao seu redor. Os participantes passaram a perceber que, ao agir de determinada forma, poderiam influenciar os outros e tomar decisões acerca de situações que lhes diziam respeito. O uso deste treino resultou, de forma geral, em uma maior independência de ação e de comunicação dos participantes em relação ao grupo controle.

Há, na atualidade, uma crescente identificação de pessoas com autismo que possuem um diagnóstico de deficiência intelectual associada. Muitos estudos 
têm sugerido o uso do chamado suporte comportamental positivo e de comunicação funcional para promover a integração e independência dessas pessoas. Um exemplo recente é o estudo de Winborn-Kemmerer et al. (2009). Esses autores buscaram ensinar respostas comunicativas a pessoas que se comportavam de "forma problemática" de acordo com pessoas próximas a elas. Os autores descobriram qual era o resultado desses comportamentos-problema e ensinaram comunicações alternativas, que geravam esses mesmos resultados, porém, sem colocar os participantes e as pessoas próximas a eles em situações de risco de agressão. Após ensinar diversas formas de comunicação alternativa, os autores permitiram aos participantes escolher dentre as comunicações ensinadas a que mais lhe aprazia. Os resultados da possibilidade de escolha mostraram que a diversas formas de comunicação foram efetivas para conseguir os resultados esperados. Porém, os participantes demostraram preferências claras por uma das formas e cada um dos participantes escolheu formas diferentes. Esta pesquisa pode ser considerada um exemplo de que é possível não apenas substituir comportamentos-problema por comunicação alternativa, mas também é possível, participantes com deficiências intelectuais severas, associadas ao autismo, escolher dentre diversas formas de comunicação.

Além de pesquisas, movimentos sociais baseados na autodefensoria, como o "Nada sobre nós sem nós" (Nothing About us Without us), têm utilizado o resultado de pesquisas participativas em conjunto com resultados de pesquisas experimentais para promoverem mudanças em políticas públicas em relação à deficiência. Leis e decretos que asseguram a acessibilidade a prédios públicos são, por exemplo, derivadas desse tipo de movimentos sociais.

Os estudos e movimentos acima referidos permitem a inferência de que é importante ensinar às pessoas com deficiência, inclusive pessoas com deficiência intelectual, seus direitos e como reivindicá-los. As técnicas utilizadas parecem ser meios efetivos de ensinar as habilidades a partir de modificações de ambientes sociais e físicos que permitem a participação dessas pessoas em todos os contextos.

\section{Conclusão}

Os resultados apresentados demonstram que modificações nos ambientes físicos e sociais e o uso de formas de ensino que promovam a independência, autonomia e escolhas podem resultar na participação de pessoas com deficiência, inclusive com deficiência severa.

A teoria de Habermas tem sido indicada como uma das formas de se olhar para todas as pessoas, com respeito às suas diferenças. Porém, a teoria de Habermas tem como base outras teorias, que pressupõem um "corpo não deficiente" para que se possa fazer parte do discurso, da ação e da interlocução. Cabe aqui a retomada da questão inicial: é possível a participação de pessoas com deficiência(s) no discurso, na ação e na interlocução tendo por base a Ética do Discurso de Habermas, 
principalmente em relação àquelas pessoas cuja deficiência é tão severa que sua estrutura corporal (no caso de paralisias cerebrais) ou o tempo de duração de sua vida não permitiria que ela conseguisse vocalizar ${ }^{8}$ suas escolhas e preferências? $\mathrm{O}$ que poderia ser feito em relação a essas pessoas quando se tem em vista sua participação no Discurso? Elas poderiam ser consideradas aptas a participar da elaboração das normas que regem suas vidas em sociedade sob o ponto de vista de uma Ética do Discurso? A Ética do Discurso seria realmente possível para essas pessoas se fossemos considerar as pressuposições de Habermas de forma literal e apenas considerar o discurso daquelas pessoas que podem efetivamente falar oralmente, sem restrições? Ou deveríamos começar a pensar em formas de fazer essas pessoas serem ouvidas, seja através de adaptações ambientais ou do ensino de formas de comunicação alternativa tanto a essas pessoas, quanto à comunidade em geral?

De forma geral, quando se pensa na Ética do Discurso proposta por Habermas, pensa-se apenas em pessoas que são capazes de falar por si mesmas "naturalmente", sem ter de haver modificações ambientais ou sem haver a necessidade de programação de procedimentos de ensino específicos ${ }^{9}$. Apesar das discussões acerca da inclusão, acessibilidade e participação de pessoas com deficiência, muitas teorias que discutem esses tópicos em relação aos seres humanos em geral tem por base o não deficiente e sequer refletem acerca das pessoas com deficiência, como é o caso da Ética do Discurso proposta por Habermas. Apesar de trazer pressupostos que poderiam engendrar, em teoria, a participação de todos os concernidos no discurso, na ação e na interlocução, a teoria de Habermas é centrada na valorização de um corpo não deficiente e talvez não seja ideal para fundamentar a busca ou a luta por equidade de respeito e de oportunidades.

A sugestão das autoras do presente trabalho é que se busquem formas de tornar disponíveis as ferramentas que possam levar a pessoa com deficiência a fazer escolhas e a expressar sua vontade, isto é, a serem autônomas. Com essa autonomia, adicionada a modificações nos ambientes sociais e físicos, pessoas com deficiência poderão participar das esferas do discurso, da ação e da interlocução, fazendo parte, efetivamente, de tomadas de decisões concernentes a sua vida. Tal participação refletiria a validez das normas que dizem respeito diretamente a elas, o que nos leva a pensar que um processo efetivo de inclusão e de busca pela igualdade pode ser construído. Talvez o que há de mais relevante na Ética do Discurso de Habermas seja o problema que tal teoria leva a sociedade humana enfrentar. A partir da ideia de que a validez de uma norma depende do assentimento de todos os concernidos, imediatamente a questão que surge é a de como construir esse ideal, como incluir todos os concernidos na busca pelo entendimento. Todavia,

\footnotetext{
${ }^{8}$ Vocalizar significando dizer oralmente.

9 Tem-se ainda a compreensão de que um deficiente intelectual não é capaz de ser um sujeito moral, isto é, um sujeito que delibera autonomamente. Pensa-se que ele somente pode reproduzir de forma acrítica os valores que lhe foram ensinados. Contudo, pesquisas na área de comunicação alternativa (RHEA, 1997; SCHWEIGERT, 1989; SCHWEIGERT; ROLAND, 1992) vêm demonstrando que, a partir da aquisição dos primeiros repertórios linguísticos, o indivíduo passa a atuar sobre seu meio de forma autônoma.
} 
parece-nos que a principal questão diz respeito ao apreço à pluralidade humana. A necessidade de se estabelecer acordos entre todos os sujeitos envolvidos, se realmente quisermos o entendimento e a validez das normas, nos conduz a olhar com respeito e tolerância as diferenças e nos faz, enquanto humanidade, encontrar soluções para incluir a todos indistintamente nas discussões que dizem respeito às suas vidas. Portanto, não se trata apenas de verificar a possibilidade ou não de se adequar a teoria da ação comunicativa de Habermas a pessoas com deficiência, no sentido de verificar se essas pessoas correspondem aos requisitos de tal teoria, mas trata-se de reconhecer o compromisso humano para com a pluralidade e a dignidade humana.

\section{REFERÊNCIAS}

BEAMISH, W.; BRYER, F. Program quality in Australian early special education: an example of participatory action research. Child: Care, Health and Development, Hoboken, v.25, n.6, p.457-472, 1999.

BRASIL. Decreto $n^{\circ}$ 3.956, de 8 de outubro de 2001. Promulga a Convenção Interamericana para a eliminação de todas as formas de discriminação contra as pessoas portadoras de deficiências. Brasília, D.F. Disponível em: <http://www.planalto.gov.br/ ccivil_03/decreto/2001/D3956.htm.> Acesso em: 22 jul. 2010.

BROWDER, D.; COOPER, K.; LIM, L. Teaching adults with severe disabilities to express their choice of setting for leisure activities. Education and Training in Mental Retardation, and Developmental Disabilities, Arlington, v.33, n.3, p.228- 238, 1998.

CHARLTON, J. I. Nothing about us without us: disability oppression and empowerment. Berkeley: University of California Press, 2000.

CONDELUCI, A. Cultural shifting: Building inclusive communities. Palestra apresentada no congresso Community Participation by People with Disabilities: How do we measure up? Overland Park, KS. 2010.

COOPER, K.; BROWDER, D. Enhancing choice and participation for adults with severe disabilities in community-based instruction. Journal of the Association for Persons with Severe Handicaps, Baltimore, v.23, n.3, p.252-260, 1998.

GLAT, R. Auto-defensoria - movimento de auto-determinação e autonomia das pessoas com deficiência mental. In: CONGRESSO ESTADUAL DAS APAES, 9., Minas Gerais, 2004. Anais.... Belo Horizonte, 2004. 1CD.

GOODLEY, D.; LAWTHOM, R. Epistemological journeys in participatory action research: alliances between community psychology and disability studies. Disability $\&$ Society, Londres, v.20, n.2, p.135-151, 2005.

HABERMAS, J. Consciência moral e agir comunicativo. Tradução de Guido A. de Almeida. Rio de Janeiro: Tempo Brasileiro, 1989a.

. Para o uso pragmático, ético e moral da razão prática. Revista de Estudos Avançados da USP, São Paulo, v.3, n. 7, p. 4-19, 1989b. 
JURKOWSKI, J. M.; FERGUSON, P. Photovoice as participatory action research tool for engaging people with intellectual disabilities in research and program development. Intellectual and Developmental Disabilities, Washington, D.C., v.46, n.1, p.1-11, 2008.

LEMESURIER, N. et al. Guide to services for young people with intellectual disabilities and mental health problems: technical document. University of Birmingham: Birmingham, 2007. Disponível em: <www.ldtransitionguide.bham.ac.uk>. Acesso em: 20 de maio 2011.

LONGMORE, P. Images of disabled people in television and motion pictures. In: GARNER, A; JOE, T. (Eds.). Images of the disabled, disabling images. New York: Praeger, 1987. p.65-78.

ORGANIZAÇÃO MUNDIAL DE SAÚDE. CID -10. Tradução do Centro Colaborador da OMS para a Classificação de Doenças em Português. 9. ed. rev. São Paulo: EDUSP, 2003.

PAGE, R. C. et al. Assertiveness training groups with the disabled: a pilot study. Journal of Rehabilitation, Londres, v.47, n.2, p.52-55, 1981.

PESSOTTI, I. Deficiência mental: da superstição à ciência. São Paulo: EDUSP, 1984.

RAWLINGS, M.; DOWSE, L.; SHADDOCK, A. Increasing the involvement of people with an intellectual disability in choice making situations: a practical approach. International Journal of Disability, Development, and Education, Londres, v. 42, n. 2, p. 137-153, 1995.

RHEA, P. Facilitating transitions, in language development for children using AAC. Augmentative and Alternative Communication, Toronto, v.13, n.3, p.141-147, 1997.

SAMPLE, P. L. Beginnings: participatory action research and adults with developmental disabilities. Disability \& Society, Londres, v.11, n.1, p.317-332, 1996.

SCHWEIGERT, P. Use of microswitch technology to facilitate social contingency awareness as a basis for early communication skills. Augmentative and Alternative Communication, Toronto, v.5, n.3, p.192-198, 1989.

SCHWEIGERT, P.; ROLAND, C. Early communication and microtechnology: instructional sequence and case studies of children with severe multiple disabilities. Augmentative and Alternative Communication, Toronto, v.8, n.4, p.273-286, 1992.

SIEVERT, A. L.; CUVO, A. J.; DAVIS, P. K. Training self-advocacy skills to adults with mild handicaps. Journal of Applied Behavior Analysis, Lawrence, v.21, n.3, p.299-309, 1988.

WARD, K.; TRIGLER, J. S. Reflections on participatory action research with people who have developmental disabilities. Mental Retardation, Washington, D. C., v.39, n.1, p.57-59, 2001.

WINBORN-KEMMERER, L. et al. A demonstration of individual preference for novel mands during functional communication training. Journal of Applied Behavior Analysis, Lawrence, v. 42, n.1, p.185-189, 2009. 